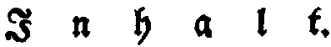

\section{Eptide Bet}

Geite

1. $\mathfrak{U}_{n}$ ben fionig von şretepen, friebrid ben 3̧weiten. . 3

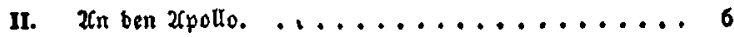

III $x_{m y n t}$ unt 6hloe. ............... 8

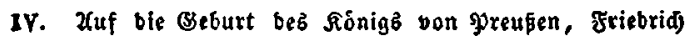

25silfjelms beb 3tweiten. $(1744.) \ldots \ldots$. . . . 10

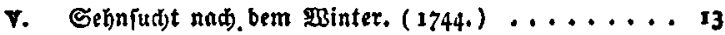

v. $2(n$ galagen. $(1745.) \ldots \ldots \ldots \ldots$. . . . . . . Is

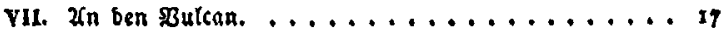


VIII. Senie auf ben 200 eits

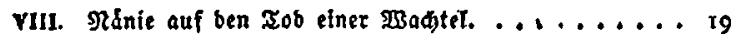

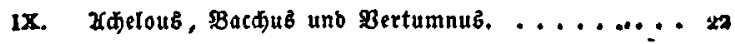
z. Uranienz \&ob gerlinz. (1749.) . . . . . . . 27

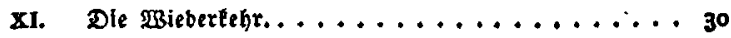

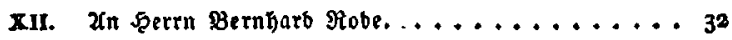

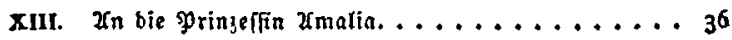
xIV. Un bie Stabt Berin. (1759.) . . . . . . 38

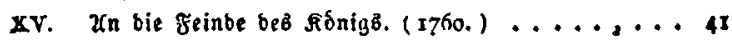
XVI. $2(n$ ben frieben. $(1760) \ldots \ldots \ldots 4$ Xv1l. Eieb ber $\mathfrak{N y m p h e ~ s p e r f a n t e . ~ ( 1 7 6 0 . ) ~ \ldots . . . . . ~} 47$

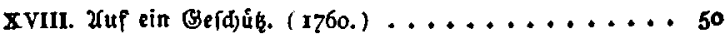
XIX. Un ben S̈lterreidiðđen Fabtub. (1760.) .....5 53 Xx. Un die Ronige. $(\pi / 6 r.) \ldots \ldots \ldots \ldots 5$

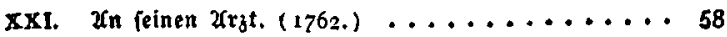
xxıI. $x_{\mathfrak{n}}$ jeinen zreunb Eycibab. ...........60

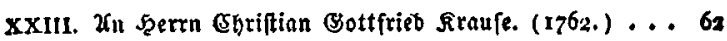
xxir. $\mathfrak{U}_{n}$ Dèlien. . . . . . . . . . . . . . 64 XXY. 2un bie ssottin ber Eintradt. (1762.) ..... 67

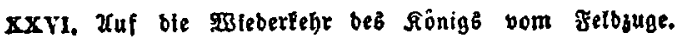
(1763.) ....................69 xxr11. xn Eatinetten. ................72 
Seite

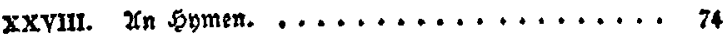

xxux. zin bie mule. ................. 76

XXX. Glaucub gahriagung. .......... 79

XXX1. Der Triumph. ............... 85

XXXII. 2(n ben Eeneralleutnent von \$Bubenbroc. . . 89

XxxIII. ubfdieb von ben f̧elben. ........... g1

xxxiy. Die Jahresfeier. .............. 94

XXXY. gुtolemñub unb Berentce. $(1765.) \ldots \ldots$

XXXXI. 2fuf ben Tob bes gुrinzen Friebrid) Sefurid

farl. $(1767.) \ldots \ldots \ldots . . . . . .100$

xxxvil. 2un bie glebe. (1768.) . . . . . . . . I03

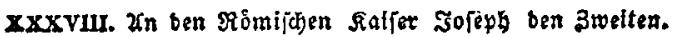

(rz6g.) ................. cos

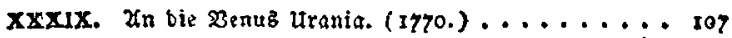

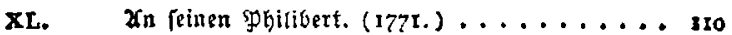

xLI. Goladitgefang. (1778.) .......... 112

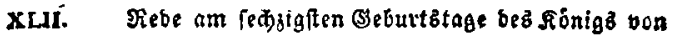

Freuten Frlebridjs bes \$̧weiten. (1772.) . . . I14

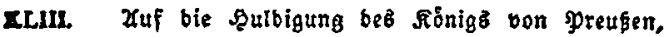

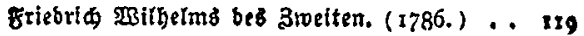

xLIY. Dte Bruberliefe, (z789) . . . . . . 128 


\section{$m$ VIII $\cdots$}

zLY. Xuf ble surudatunft bes sönigs von spreusen,

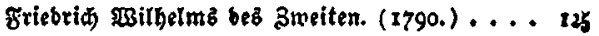

xl. Zn bie fionigin von preufen Frieberife \&uife,

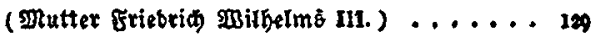

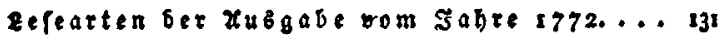

Xnmertangen. ................. 